\title{
ESTRATÉGIAS PARA O ENSINO REMOTO DA DISCIPLINA METROLOGIA INDUSTRIAL
}

DOI: 10.37702/2175-957X.COBENGE.2021.3618

Fabiana Rodrigues Leta - fabianaleta@id.uff.br

Universidade Federal Fluminense

R. Voluntários da Pátria 100

22270-010 - Rio de Janeiro - RJ

Caio Brandão da Costa - caiobc@id.uff.br

Universidade Federal Fluminense

Rua das Amendoeiras 164

23056-620 - Rio de Janeiro - RJ

Resumo: Durante a pandemia do COVID-19, foi necessário pensar em novas estratégias para superar os desafios do ensino remoto de Metrologia Industrial. A inovação já estava presente nesta disciplina, onde as práticas laboratoriais estavam gravadas em vídeos. Porém foram necessárias adequações, envolvendo o processo de avaliação e a metodologia de ensino. Assim, foram desenvolvidas atividades de avaliação contínua que envolveram o conceito de sala de aula invertida. Para atingir os objtivos do curso estimulou-se a reflexão de exemplos práticos reais, relacionados ao cotidiano dos alunos e a projetos acadêmicos. Os alunos tiveram ainda que desenvolver experimentos de avaliação da conformidade de forma caseira, criando alternativas a procedimentos realizados em laboratórios. Os resultados positivos obtidos demonstram que parte destas estratégias deverão permanecer no retorno do ensino presencial.

Palavras-chave: Metrologia Industrial, Ensino Remoto, Aprendizado por Projeto, Avaliação Contínua 


\section{ESTRATÉGIAS PARA O ENSINO REMOTO DA DISCIPLINA METROLOGIA INDUSTRIAL}

\section{INTRODUÇÃO}

Metrologia é a ciência que trata das medições como um todo, abrangendo aspectos teóricos e práticos relativos às medições (INMETRO, 2012). No curso de Engenharia Mecânica da Universidade Federal Fluminense é oferecida a disciplina Metrologia Industrial, para os alunos do $5^{\circ}$ período. No contexto da pandemia Covid 19 apresentar esta disciplina tornou-se um desafio, especialmente em função da parte prática envolvida. Além disso, diversas peculiaridades do ensino remoto, envolvendo atendimento assíncrono e adaptação às novas tecnologias se tornam fundamentais na busca por inovação no ensino dessa disciplina tão importante para a formação de profissionais de Engenharia Mecânica.

Dando continuidade a trabalhos anteriores, onde foram desenvolvidos conteúdos referentes às aulas de laboratório da disciplina Metrologia Industrial (LETA et al., 2017a), incluindo os seus registros em vídeos (LETA et al., 2017b), no presente artigo apresentamse as estratégias adotadas para o ensino remoto nos períodos de 2020-1 e 2020-2. Antes da pandemia havia aulas práticas ministradas no Laboratório de Metrologia Dimensional e Computacional, que era um dos espaços de reflexão e discussão sobre os conteúdos da disciplina, além da sala de aula. Apesar das videoaulas estarem disponíveis desde 2017, estas eram usadas apenas como material de apoio ao estudo pelos alunos.

Com a pandemia, a disponibilização de ferramentas digitais pela instituição de ensino, como as planilhas Google, estimulou a criação de exercícios que motivassem a curiosidade para questões técnicas, envolvendo a aplicação da Metrologia a projetos e avaliação da qualidade de produtos. A aplicação dos conceitos de Metrologia em projetos já fazia parte da metodologia adotada na disciplina, a cada semestre escolhe-se uma peça real desenvolvida em um projeto de extensão da Escola de Engenharia e realiza-se a avaliação do seu dimensionamento, considerando cotas, tolerâncias e ajustagem e a forma de medi-los. O que antes era feito no laboratório passou a ser trabalhado de forma remota. Com isto foi possível explorar também ferramentas disponíveis em planilhas eletrônicas, envolvendo o uso de fórmulas, cálculos automatizados e organização de dados. Possibilitar este aprendizado aos alunos trouxe um ganho positivo, visto que estes percebem que é um conhecimento que vem sendo exigido em processos seletivos de estágios em Engenharia Mecânica. Houve ainda uma adaptação à forma de atendimento por parte do monitor, que antes se dava de forma presencial e passou a ser realizado mais intensamente através de aplicativo de mensagens instantâneas, se mostrando bastante eficaz na aproximação com os discentes matriculados.

Neste contexto, no presente artigo apresenta-se a metodologia adotada para o ensino remoto da disciplina Metrologia Industrial, apontando as adaptações que se fizeram necessárias e seus aspectos positivos, que devem ser permanecer pós pandemia.

\section{METODOLOGIA}

Foram utilizadas diversas estratégias, buscando a inovação, para o ensino da disciplina Metrologia Industrial, que tem a seguinte ementa:
I. Definições;
II. Histórico;
III. Sistemas de unidades; 
IV. Tolerâncias Dimensionais;

V. Sistemas de Tolerâncias e Ajustes;

VI. Tolerâncias Geométricas;

VII. Princípios e Terminologia de Medição;

VIII. Estrutura Metrológica;

IX. Acreditação;

X. Certificação de produtos e serviços;

XI. Instrumentos de medição;

XII. Rugosidade;

XIII. Estatística aplicada à Metrologia;

XIV. Incerteza de Medição;

XV. Avaliação da Conformidade.

Para tratar estes conteúdos foram adotadas as seguintes estratégias através da plataforma Google Classroom:

1. Disponibilização dos slides apresentados nas aulas síncronas;

2. Desenvolvimento de questionários de avaliação contínua referentes aos conteúdos das aulas síncronas;

3. Videoaulas de práticas de laboratórios (assíncronas);

4. Apresentação de dados de medição referentes às práticas (videoaulas) para a realização de exercícios;

5. Desenvolvimento de um caso de estudo de delineamento dimensional;

6. Proposta de estudo e desenvolvimento de testes para avaliação da conformidade de produtos;

7. Prova remota envolvendo os conteúdos de Estatística e Incerteza de Medição.

Os slides apresentados nas aulas síncronas foram adaptados para a nova realidade, tornando-se mais atrativos visualmente e passando a inserir referências a vídeos, que não apenas complementam os conteúdos, mas trazem ainda um dinamismo às aulas. Cabe ressaltar que no ensino presencial nem sempre era possível apresentá-los por limitações quanto à tecnologia disponível em sala de aula (rede e som).

A disciplina, no aspecto pedagógico e avaliativo, foi dividida em cinco fases. A primeira introdutória, que envolvia uma revisão de conteúdos prévios, onde a reflexão sobre a importância e a aplicação da Metrologia eram o principal foco. Para esta fase adotou-se o desenvolvimento de questionários de avaliação.

Embora seja meio óbvia a necessidade de se desenvolver um processo de avaliação contínua em qualquer disciplina, isto não ocorria na disciplina de Metrologia Industrial no ensino presencial, onde adotavam-se duas a três avaliações por período. Mas com o ensino remoto esta indicação passou a ser um processo importante e relevante. Neste ponto a disciplina pode contar com um monitor que, ao exercer a iniciação à docência, foi incentivado a desenvolver e propor questionários de avaliação complementar às aulas.

A fase dois refere-se à apresentação das videoaulas em substituição às aulas práticas presenciais. Na página do Laboratório de Metrologia Dimensional e Computacional (LETA et al., 2017), os discentes possuem acesso tanto aos procedimentos quanto às videoaulas referentes às práticas de laboratório. A criação desse conteúdo audiovisual foi realizada em um período anterior à pandemia e foi bastante proveitoso para o ensino da disciplina, onde os discentes puderam ver as atividades que iriam realizar em laboratório. Avalia-se que pensar em transformar os conteúdos apresentados em materiais assíncronos é uma estratégia bastante válida para que os discentes possam compreendê-los no tempo que precisarem. No período remoto percebeu-se a necessidade de apresentar as 
videoaulas e o material de apoio de modo a fazer com que os alunos se sentissem realizando as medições no laboratório. Para isto os dados das medições das aulas práticas foram disponibilizados e os alunos tiveram que trabalhar estes dados por meio de planilhas eletrônicas, se familiarizando com os recursos de organização e formulações matemáticas disponíveis, para responderem às questões solicitadas em cada aula.

A fase três refere-se a um estudo de caso, onde os alunos são estimulados a refletir e planejar o delineamento de medição de uma peça real. Esta atividade já ocorria no ensino presencial, mas teve que sofrer adaptações para possibilitar o aprendizado dos alunos, motivando-se reuniões remotas e discussões via grupo de mensagens com o monitor, que antes eram feitas presencialmente. Tradicionalmente se opta por peças relacionadas aos projetos de extensão de competição do curso de Engenharia Mecânica.

A quarta fase trata do conteúdo de avaliação da conformidade de produtos. Este tipo de atividade já havia sido desenvolvido anteriormente na disciplina. Para o período remoto o desafio foi a realização de ensaios e testes de produtos em casa, sem os materiais e equipamentos disponíveis nos laboratórios da universidade.

E por fim a última fase que correspondeu a uma prova com exercícios envolvendo os conteúdos finais da disciplina, onde os alunos foram mais uma vez estimulados a desenvolverem as respostas em planilhas digitais, aprendendo a manipular dados e usar funções matemáticas e estatísticas disponíveis nas planilhas.

Com esta dinâmica, a avaliação dos discentes foi feita ao longo de todo o semestre letivo, nas diversas fases destacadas. Com o atendimento assíncrono, dúvidas foram tiradas no grupo e de forma individualizada, onde se viu um maior engajamento dos discentes durante a execução das atividades, do que o observado no ensino presencial.

\section{RESULTADOS}

Apresentam-se neste item alguns resultados obtidos nas fases 1 a 5 desenvolvidas na disciplina Metrologia Industrial durante os dois períodos remotos decorrentes da pandemia.

\subsection{Questionários de avaliação contínua}

Nesta fase foram desenvolvidos três questionários relacionados aos conteúdos iniciais da disciplina, para a fixação dos conteúdos teóricos apresentados durante as aulas, como o que pode ser visto na Figura 1.

Para uma melhor absorção dos conteúdos teóricos, a exemplificação através de itens cotidianos, como um telefone celular, se fez presente para contornar os desafios do ensino remoto de Metrologia Industrial. Essa estratégia foi bastante efetiva em provocar os discentes a compreenderem como é o uso desta disciplina em diversos lugares da cadeia industrial. Na Figura 2, é possível visualizar uma resposta de um dos discentes sobre uma das perguntas do formulário. Através desta verbalização, é possível compreender que trazer exemplos mais próximos dos estudantes, à luz da sala de aula invertida, se mostra bastante interessante para a compreensão dos conteúdos. 


\section{Metrologia Industrial - Aulas 4 e 5}

Formulário para ser preenchido após a aula. A ordem das perguntas está de acordo com o conteúdo a ser trabalhado e este formulário serve para a fixação e visualização dos conceitos apresentados.

E-mail *

Endereço de e-mail válido

Este formulário coleta endereços de e-mail. Alterar configurações

Laboratório de Metrologia Dimensional e Computacional

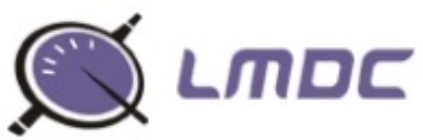

A imagem abaixo mostra um desenho técnico do telefone celular Apple iPhone 12 Pro Max.

\section{2 iPhone 12 Pro Max 2 of 2}

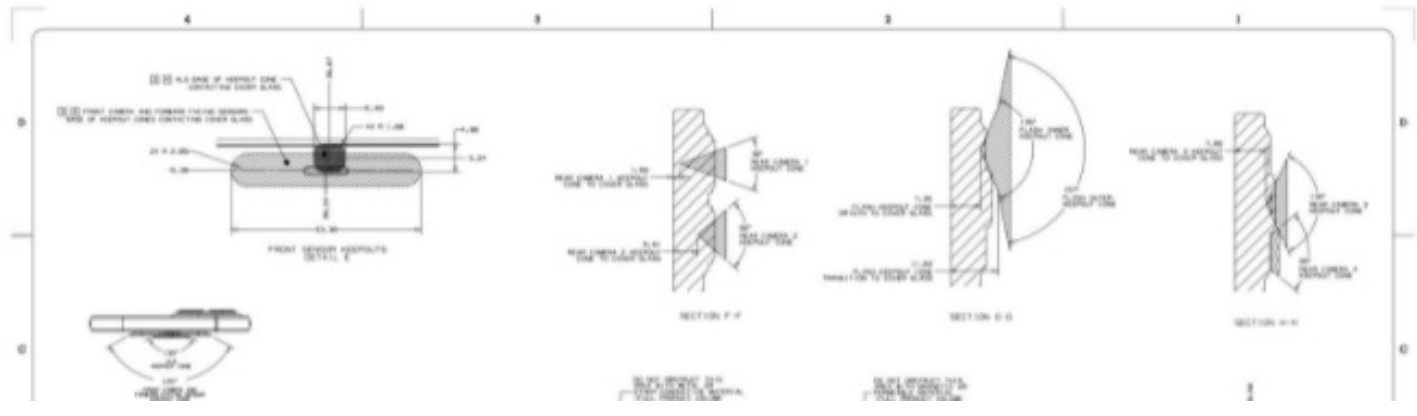

Fonte: autores. 
Figura 2 - captura de tela que mostra uma resposta

de um dos discentes da disciplina.

\title{
Cite e explique duas tolerâncias dimensionais e duas tolerâncias geométricas que considera relevantes em um telefone celular.
}

Tolerâncias Dimensionais: - A tolerância ISO (afastamentos) é, julgo eu, de extrema importância para o correto funcionamento de aparelhos sofisticados como o telefone celular, pois permite que peças pequenas, normalmente de difícil e precisa produção, possam ser feitas com um grau de erro mais abrangente. Desta forma, garante-se uma produção com potencial funcionalidade sem exigir nessa produção uma precisão absurda, precisão que aumentaria o preço do produto; - A rugosidade também se faz muito relevante na construção de um aparelho celular, pois (além de garantir um produto esteticamente agradável, tanto à visão quanto ao toque físico) é uma medida que viabiliza o bom funcionamento de certas peças presentes no produto, como a tela touchscreen e a antena de sinal interna. Tolerâncias Geométricas: - A planicidade, de maneira semelhante à rugosidade (supracitada) garante que certas peças funcionem do jeito que o projeto pretende que tais peças funcionem; - A concentricidade é essencial para o bom funcionamento do celular, uma vez que exige que as peças estejam localizadas em uma posição específica (em relação a outras peças). Caso contrário, supondo que a tolerância não fosse aplicada, há um risco muito grande da peça em questão não trabalhar da maneira planejada, o que consiste em uma falha no produto que pode até ocasionar a necessidade de um descarte.

1 resposta

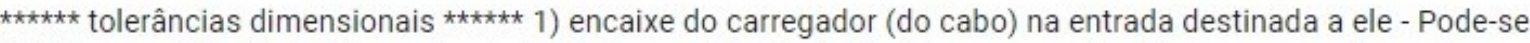
definir como tolerância dimensional de ajuste com interferência, já que para a fixação do carregador no furo destinado a ele seja possível ( o carregador precisa estar fixado o tempo todo do carregamento) é necessário ter um encaixe com um certo "esforço" que fixe-o no furo. 2) botão para desligar e ligar o celular - para que o botão entre - quando apertamos - e saia ( volte para sua posição padrão) - quando soltamos - é necessário se ter uma tolerância dimensional de ajuste com folga, para que com o movimento de apertar e soltar ocorra sem

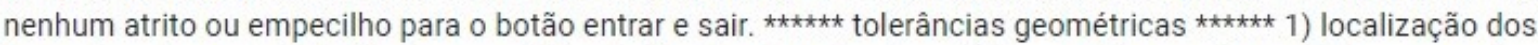
furos das câmeras - Tolerância geométrica do tipo localização - *posição* - analisa qual a posição que a parte indicada está em relação ao todo . 2) orientação do furo superior de saída de áudio em relação a superficial limite do aparelho Tolerância geométrica do tipo orientação - *paralelismo* - define o paralelismo entre duas partes desenhadas. Nesse caso o paralelismo entre a linha da superfície limite de borda do aparelho, e a linha
\end{abstract}

Fonte: autores.

\subsection{Videoaulas}

A disciplina dispõe de nove aulas práticas na forma de procedimentos e videoaulas, envolvendo os seguintes tópicos: paquímetro, micrômetro, relógio comparador, projetor de perfis (duas aulas), microscópio de medição, nível laser, verificação geométrica de torno mecânico e verificação geométrica de plaina limadora. As aulas práticas visavam que os alunos aprendessem a usar corretamente os instrumentos em casos práticos. Além disso a cada aula, envolvendo instrumentos de medição, associa-se o aprendizado de conceitos 
de tolerâncias e ajustagens ensinados nas aulas teóricas, como pode ser visto no exemplo apresentado na Figura 3.

Com o ensino remoto foi possível explorar parcialmente o aprendizado do uso dos instrumentos, visto que os alunos não têm acesso físico aos instrumentos. Porém quanto ao entendimento dos conteúdos teóricos na prática entende-se que se alcançou os objetivos, pois foram apresentados dados reais das medições que foram analisados pelos alunos, analogamente ao que fariam no ensino presencial.

Na Figura 4, apresenta-se um exemplo de um dos exercícios trabalhados, referente à vídeo aula de paquímetro, onde são tratados conceitos de tolerância dimensional e ajustagem. Os dados da Figura 10 foram obtidos das anotações do técnico responsável pelo acompanhamento da disciplina, em conjunto com o monitor e com a docente. Serviram de base para que os discentes pudessem aplicar seus conhecimentos sobre os conceitos apresentados na videoaula, como paralelismo, retilineidade e planicidade, dentre outras coisas. Sendo, portanto, uma estratégia de ensino ativa e que apresenta a importância tanto dos conteúdos apresentados na disciplina quanto do domínio de aplicativos usuais para Engenharia, que complementam o que foi aprendido.

Figura 3 - Atividade referente à videoaula sobre relógio comparador.

\section{自 Vídeo aula 3 - relógio comparador}

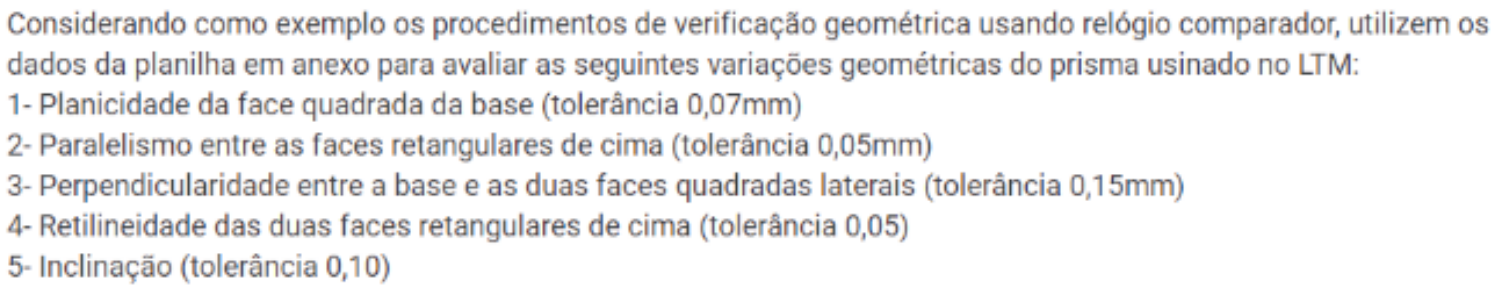

Para facilitar a compreensão das medidas que o apresenta na planilha, o preparou alguns desenhos e vídeos, todos em anexo.
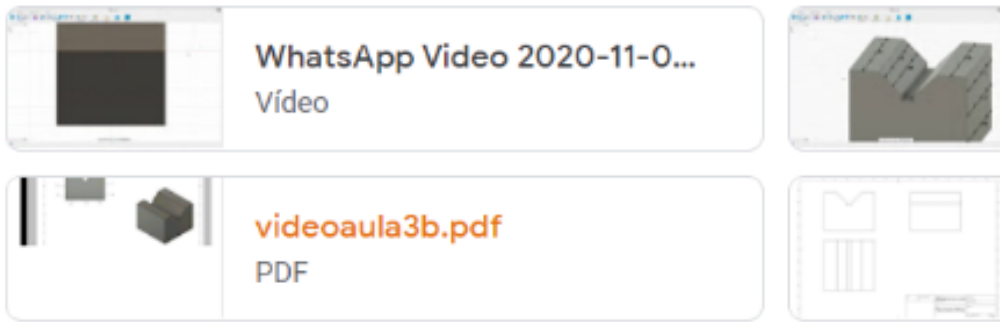

WhatsApp Video 2020-11-0... Vídeo

Fonte: autores

videoaula3.pdf PDF 
Figura 4 - Uso de planilhas eletrônicas para a solução da atividade proposta.

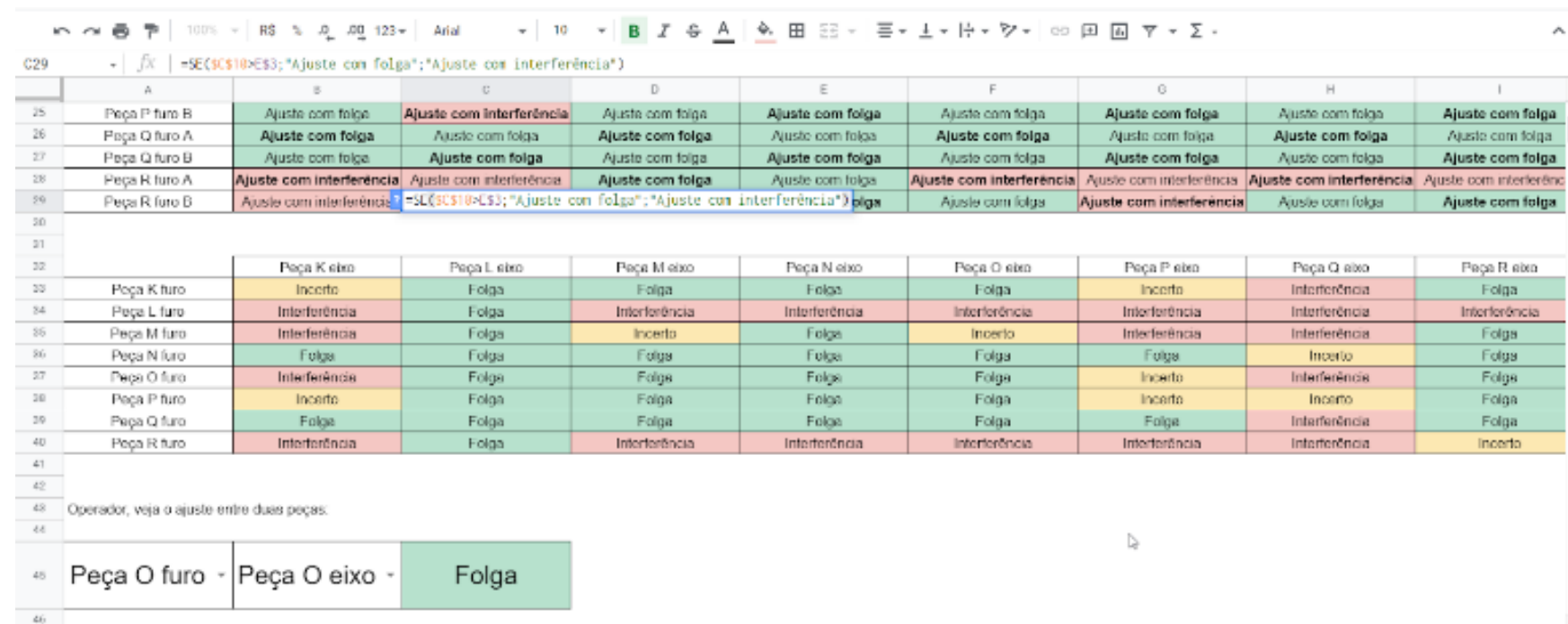

Fonte: autores.

\subsection{Delineamento dimensional}

Um dos objetivos da disciplina é apresentar a Metrologia de uma forma mais prática de modo a despertar o interesse dos alunos, que com isto se apropriam mais facilmente do conhecimento relacionado. A atividade de delineamento dimensional vem ao encontro deste objetivo, pois envolve peças desenvolvidas em projetos de extensão da Escola de Engenharia da Universidade Federal Fluminense. Nestes dois semestres adotou-se o projeto de foguetemodelismo. O projeto, construção e montagem do foguete foi apresentado para a turma, que foi instigada a refletir sobre questões tolerância e ajustagem conforme as exigências funcionais do foguete. Na Figura 4, é possível ver a proposta apresentada para a elaboração do trabalho sobre delineamento.

Trazer também assuntos como manufatura aditiva e laminação manual de fibra de vidro foi importante para os discentes. Na Figura 5, pode-se vislumbrar o uso da metodologia de sala de aula invertida. Apresenta-se uma das respostas de alunos, que demonstra a reflexão sobre diversos assuntos vistos, sendo provocados a pensar no ferramental teórico obtido na disciplina, como tolerâncias dimensionais e geométricas, complementando-os visando uma interface em indústrias de ponta, como a de impressão $3 \mathrm{~d}$ nos componentes construídos pela manufatura aditiva da indústria 4.0, a de fibra de vidro e a própria aeroespacial, que serviu de referencial teórico para a equipe de foguetemodelismo. Portanto, mesmo no ensino remoto, é possível aguçar a curiosidade e mostrar a importância da metrologia industrial através de estratégias que aproximem os discentes com o que eles almejam para as suas carreiras como profissionais de engenharia mecânica. 
Figura 4 - Perguntas do formulário sobre componentes de um foguete.

As fotos abaixo são de um foguete amador da equipe de pesquisas aeroespaciais LUFFT. À esquerda, é possivel ver o tubo do motor (casing) e o anel de fixação. No meio, é possivel ver a estrutura externa (fuselagem) e o mesmo anel de fixação internamente, além das aletas, desfocadas. À direita, é possivel ver as aletas de perfil, a estrutura externa e a tubeira metálica, detalhada na figura mais abaixo, que é um dos componentes do motor do foguete. $O$ casing e a tubeira foram fabricados em aço inoxidável AISI 316, o anel de fixação foi fabricado em uma impressora 3d e a fuselagem externa, laminada manualmente em fibra de vidro.
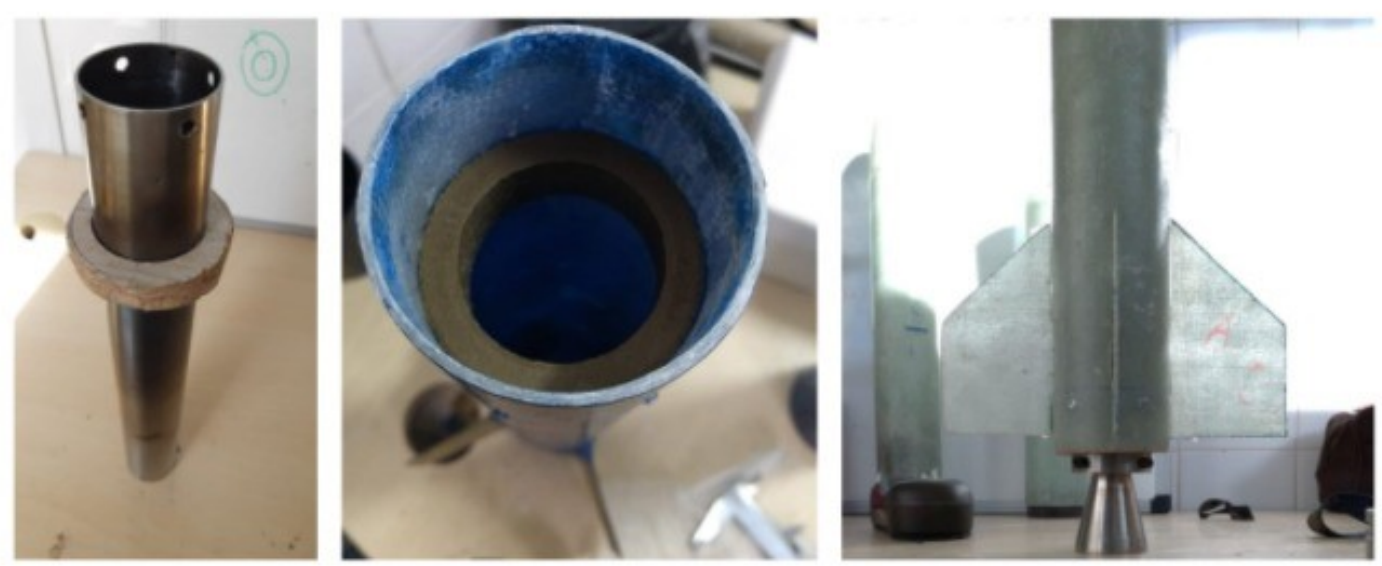

Fonte: autores. 
Figura 6 - Uma das respostas do formulário sobre componentes de um foguete amador

Recapitulando o que você viu nas aulas sobre tolerância geométrica e nos demais exercícios deste formulário, expandindo seu conhecimento como futuro profissional de engenharia mecânica, quais tolerâncias dimensionais e geométricas você identifica neste projeto real de engenharia? Através dos processos de fabricação utilizados (torneamento, manufatura aditiva e laminação manual de fibra de vidro) que classe de tolerância você inferiria no projeto: 1. do casing (um tubo comercial); 2. da tubeira (torneamento); 3. do anel de fixação (manufatura aditiva) e; 4 . estrutura externa (laminação manual de fibra de vidro).

Como tolerância dimensional importantes neste projeto estão as tolerâncias em relção aos comprimentos, larguras e espessuras das peças bem como as famílias de tolerância furo-base (mais comumente usadas) para os diâmetros do casing, do anel de fixação e da tubeira metálica. Os tipos de ajuste bem como os tipos de acabamento superficial também são importantes, uma vez que irão especificar as tolerâncias dimensionais das peças. Para as tolerâncias geométricas importantes nesse projeto temos as tolerâncias geométricas de forma, no qual a cilindricidade é importante para o casing e para a tubeira metálica, a circularidade é importante para o anel de fixação, a planeza para as aletas. Podemos citar também as tolerâncias geométricas de orientação (paralelismo, perpendicularismo e inclinação) importantes principalmente à aerodinâmica do projeto, e as tolerâncias geométricas de posição (posição de um elemento, concentricidade e simetria) importantes para o correto encaixe das peças que compõe o projeto e correto desempenho da função estipulada para este. classe de tolerância; do casing (um tubo comercial) - IT 9-11 Construção Mecânica corrente da tubeira (torneamento)IT 7-8 Construção Mecânica cuidada do anel de fixação (manufatura aditiva)- IT 5-6 Construção Mecânica de grande precissão estrutura externa (laminação manual de fibra de vidro)- IT 12-18 Construção Mecânica grosseira ( laminagem, estampagem, fundição, forjamento)

Fonte: autores.

\subsection{Avaliação da conformidade de produtos}

Nesta atividade a proposta é o aprendizado sobre o tema avaliação da conformidade, quanto aos aspectos teóricos e práticos. Os alunos devem compreender os requisitos envolvidos na avaliação da conformidade e escolherem um produto para análise, inspirados no que já foi realizado no Inmetro (2021). O desafio desta atividade no ensino remoto envolve a escolha de produtos de baixo valor que possam ser testados em casa, tendo em vista a impossibilidade dos alunos estarem presencialmente nos laboratórios da universidade. O trabalho pode ser feito em dupla, que traz um desafio adicional de realizarem discussões de forma remota.

Os ensaios desenvolvidos pelos alunos levaram em consideração os recursos que dispunham em casa, sendo adequados a estas circunstâncias. A apresentação da atividade foi feita na forma de uma aula expositiva remota com a demonstração dos ensaios 
realizados por meio de vídeos. Alguns exemplos de produtos e ensaios apresentados nesta atividade: canetas esferográficas, garrafa térmica, sacolas plásticas, bola de basquete,tupia fresadora, benjamins, máscara de proteção, isqueiro, adaptador de tomada, aplicativo de banco, entre outros.

\section{CONSIDERAÇÕES FINAIS}

O desafio do ensino remoto foi contornado através de diversas estratégias. Um dos primeiros aprendizados foi que, antes mesmo de se aderir ao ensino remoto, é preciso criar ou dispor de conteúdos audiovisuais para que os discentes acessem os mesmos de maneira assíncrona. O uso de tecnologias como formulários e planilhas eletrônicas são extremamente bem-vindas, assim como exemplos de projetos reais de engenharia e de objetos do cotidiano dos discentes, aproximam o conteúdo visto do mundo real, inspirandose na aprendizagem de sala de aula invertida.

Por ser uma disciplina do quinto período do curso de Engenharia Mecânica, é interessante relacionar seus conteúdos com o cotidiano dos discentes. Pode-se observar nas respostas encaminhadas pelos alunos que estes passam a ter uma melhor compreensão sobre os conteúdos, ao serem indagados sobre assuntos de forma periódica, através dos formulários enviados, fixando deste modo os conhecimentos de forma contínua e perene.

Neste artigo apresentam-se as estratégias adotadas na disciplina Metrologia Industrial para o ensino remoto, a partir de metodologias de sala de aula invertida. Mesmo à distância, devido ao isolamento social, a empolgação dos discentes ao compreenderem os conteúdos apresentados na disciplina através destas novas estratégias de ensino é notória. Isto estimula que no retorno às atividades presenciais muitas destas estratégias permaneçam.

Mostrar a aplicação de conceitos de Metrologia Industrial não só na própria disciplina, mas também em outras áreas de abrangência do curso apresenta resultados interessantes. Assim, pretende-se nos próximos períodos apresentar outros tipos de aplicação. Exemplos que podem ser explorados, à luz dos exemplos do presente artigo, que abordaram manufatura aditiva e fibras de vidro, referem-se às disciplinas de Engenharia de Materiais e Engenharia de Fabricação, ao explorar as classes de tolerância para diferentes materiais e os diversos processos de fabricação, como torneamento ou usinagem por comando numérico computadorizado.

\section{REFERÊNCIAS BIBLIOGRÁFICAS}

INMETRO. Portaria n..$^{\circ}$ 232, de 08 de maio de 2012: Vocabulário Internacional de Metrologia - Conceitos fundamentais e gerais e termos associados (VIM 2012). Disponível em: http://www.abimaq.org.br/site.aspx/Certificacao. Acesso em: 17 abr. 2021.

INMETRO. Avaliação da Conformidade - Registro de Objeto. Disponível em: http://registro.inmetro.gov.br/consultal. Acesso em: 09 mai. 2021.

LETA, F.R., VIEIRA, A.R.J., RODRIGUES, L. M. Metrologia Dimensional: Aulas Práticas. 2017. 
LETA, F.R., VIEIRA, A.R.J., RODRIGUES, L.M., MACIEL, G.D. Metrologia Dimensional: Vídeo Aulas. 2017. Disponível em: http://www.Imdc.uff.br/ensino/curso.php. Acesso em: 17 abr. 2021.

\title{
STRATEGIES FOR REMOTE TEACHING OF INDUSTRIAL METROLOGY
}

\begin{abstract}
:
During the COVID-19 pandemic, it was necessary to think of new strategies to overcome the challenges of remote teaching of Industrial Metrology. Innovation was already present in this discipline, where laboratory practices were recorded on videos. However, adjustments were necessary, involving the evaluation process and the teaching methodology. Thus, continuous assessment activities were developed that involved the concept of an inverted classroom. To achieve the objectives of the course, reflection on real practical examples related to students' daily lives and academic projects was stimulated. The students also had to develop conformity assessment experiments at home, creating alternatives to procedures performed in laboratories. The positive results obtained demonstrate that part of these strategies should remain in the return of classroom teaching. Keywords: industrial metrology, remote teaching, learning by project, continued evaluation.
\end{abstract}

